\title{
To Explore the Bleaching Effect of Chlorine Water
}

\author{
Wang Haijun \\ The Beijing No 12 High School Chemical Innovation Experiment Center, Beijing, China
}

Email address:

wanghaijunbiyin@163.com

\section{To cite this article:}

Wang Haijun. To Explore the Bleaching Effect of Chlorine Water. Science Journal of Analytical Chemistry. Vol. 7, No. 1, 2019 , pp. $21-26$. doi: $10.11648 /$ j.sjac.20190701.13

Received: January 9, 2019; Accepted: February 19, 2019; Published: April 3, 2019

\begin{abstract}
In this paper, first of all, based on the chemical process of chlorine water system in-depth comprehensive analysis, aims to clear the chlorine water is composed of a variety of molecules, ions and free radicals in the complex redox system; secondly, we designed six experiments for scientific inquiry on chlorine bleaching effect under the different conditions, and give a reasonable explanation for the experimental results; finally, scientifically summed up the bleaching effect of chlorine water is a process of multiple components of synergy, many influence factors, but the "hero" is still the hypochlorous acid, the chemical principle and bleaching effect of hypochlorous acid to give a scientific explanationand and give a scientific explanation of the chemical principle of bleaching. The research methods are as follows: Contrastive experimental analysis method; Research purposes: Explain the principle and essence of Chlorine bleaching, and further clarify people's vague or even wrong understanding of Chlorine bleaching. Results and conclusions: The bleaching of chlorine water is a very complex physicochemical process with many influencing factors. The structure and properties of Hypochlorous Acid play a decisive role.
\end{abstract}

Keywords: Chlorine, Chlorine Water, Hypochlorous Acid, Oxidation, Bleaching, Photocatalytic Reaction

\section{Introduction}

At present, there is no systematic, accurate, in-depth and convincing demonstration on the principle and essence of chlorine bleaching in aqueous solution. Based on this, this paper tries to make up for the above shortcomings, throw a brick to attract jade, if there are inappropriate, please peer correction.

\section{Brief Analysis of Chlorine Water System}

The water solution of chlorine gas is simply called "chlorine water". Usually, chlorine gas is added into distilled water to produce "saturated chlorine water" (in fact, it is very difficult to produce saturated chlorine water, and generally concentrated chlorine water is obtained). The solubility of chlorine gas in water is relatively small. About $1 / 3$ of chlorine gas dissolved in saturated chlorine water reacts with water by hydrolysis disproportionation reaction [1] 126 (generally expressed by the following reaction process (4):

$$
\mathrm{H}_{2} \mathrm{O} \leftrightharpoons \mathrm{H}^{+}+\mathrm{OH}^{-}
$$

$$
\begin{gathered}
\mathrm{Cl}_{2} \leftrightharpoons \mathrm{Cl}^{-}+\mathrm{Cl}^{+} \\
\mathrm{Cl}^{+}+\mathrm{OH}^{-} \leftrightharpoons \mathrm{ClOH} \\
\mathrm{Cl}_{2}+\mathrm{H}_{2} \mathrm{O} \leftrightharpoons \mathrm{H}^{+}+\mathrm{Cl}^{-}+\mathrm{ClOH} \\
\mathrm{ClOH} \leftrightharpoons \mathrm{H}^{+}+\mathrm{ClO}^{-} \\
\mathrm{ClOH} \leftrightharpoons \cdot \mathrm{Cl}++\mathrm{OH}^{-}
\end{gathered}
$$

The essence of the above reaction process can be understood by Reaction (3). The concentration of hypochlorous acid depends on the extent to which the reaction moves to the right. Reaction (4) corresponds to the total reaction of the above two processes, in other words: the above chemical reaction $(4)=$ chemical reaction $(1)+$ chemical reaction(2)+chemical reaction (3). The so-called hydrolytic disproportionation reaction of Chlorine Gas refers to this process. Chlorine gas molecule which did not participate in the reaction will mainly exist in the form of hydrated Molecule $\left(\mathrm{Cl}_{2}\left(\mathrm{H}_{2} \mathrm{O}\right)_{\mathrm{n}}\right)$.

[Analysis] The basic principles of the above-mentioned main processes are as follows: Firstly, under the polarization of water molecule, Ghlorine Molecule $\left(\mathrm{Cl}_{2}\right)$ undergoes an unbalanced distribution of intramolecular electron clouds, 
which leads to polarization of the Molecule, so that the positive and negative charge gravity centers of the Molecule no longer coincide, and the Non-Polar Molecule of Chlorine Molecule is transformed into Polar Molecule As a result, the additional polarization of Chlorine Molecule and Water Molecule was further enhanced, resulting in further charge separation, which resulted in partial Chlorine Molecule splitting into chloride positive ion $\left(\mathrm{Cl}^{+}\right)$and chlorine negative ion $\left(\mathrm{Cl}^{-}\right)$, which then combined with hydrogen ion $\left(\mathrm{H}^{+}\right)$and hydroxide ion $\left(\mathrm{OH}^{-}\right)$ionized from Water Molecule to form Hydrogen Chloride $(\mathrm{HCl})$ and Hypochlorous Acid $(\mathrm{ClOH})$.

At $298 \mathrm{~K}$, the equilibrium concentration of each species during the above process from (1) to (5) reaching the chemical equilibrium state is roughly as follows [1] 126 (molar concentration of substance in table " $C$ " in the following formula, its dimension is " $\mathrm{molL}^{-1}$ "; "aq" is aqueous solution):

$$
\begin{gathered}
C\left(\mathrm{H}^{+}\right)=C\left(\mathrm{Cl}^{-}\right)+C\left(\mathrm{OH}^{-}\right)+C\left(\mathrm{ClO}^{-}\right) \\
C\left(\mathrm{Cl}_{2}\right)_{(\mathrm{aq})}=0.062 \mathrm{molL}^{-1} \\
C\left(\mathrm{Cl}^{-}\right)=0.031 \mathrm{molL}^{-1} \\
C\left(\mathrm{H}^{+}\right)>0.031 \mathrm{molL}^{-1} \\
C(\mathrm{ClOH})<0.031 \mathrm{molL}^{-1}
\end{gathered}
$$

Solubility of $\mathrm{Cl}_{2}: C\left(\mathrm{Cl}_{2}\right)_{(\mathrm{aq})}=0.093 \mathrm{molL}^{-1}$

Obviously, the concentration of hypochlorous acid in chlorine water is low, about $0.031 \mathrm{molL}^{-1}$. According to Le Chatelier's Principle, reducing the concentration of hydrogen and chloride ions can promote the above equilibrium (3) and (4) to the right, thus increasing the concentration of hypochlorous acid. For example, the addition of newly prepared active mercuric oxide or silver oxide to chlorinated water, which reacts with chloride and hydrogen ions to form precipitation, is used to promote the above equilibrium (3) and (4) to move to the right, thereby increasing the concentration of hypochlorite (the corner label "s" denotes the solid phase).

$$
\begin{gathered}
\mathrm{Ag}_{2} \mathrm{O}_{(\mathrm{s})}+2 \mathrm{Cl}^{-}+2 \mathrm{H}^{+} \rightarrow 2 \mathrm{AgCl}_{(\mathrm{s})}+\mathrm{H}_{2} \mathrm{O} \\
\mathrm{Ag}_{2} \mathrm{O}_{(\mathrm{s})}+2 \mathrm{Cl}_{2}+\mathrm{H}_{2} \mathrm{O} \rightarrow 2 \mathrm{AgCl}_{(\mathrm{s})}+2 \mathrm{ClOH} \\
2 \mathrm{HgO}_{(\mathrm{s})}+2 \mathrm{Cl}^{-}+2 \mathrm{H}^{+} \rightarrow \mathrm{Hg}_{2} \mathrm{OCl}_{2(\mathrm{~s})}\left(\mathrm{or}: \mathrm{HgO} \cdot \mathrm{HgCl}_{2(\mathrm{~s})}\right)+\mathrm{H}_{2} \mathrm{O}( \\
2 \mathrm{HgO}_{(\mathrm{s})}+2 \mathrm{Cl}_{2}+\mathrm{H}_{2} \mathrm{O} \rightarrow \mathrm{Hg}_{2} \mathrm{OCl}_{2(\mathrm{~s})}\left(\mathrm{HgO} \cdot \mathrm{HgCl}_{2(\mathrm{~s})}\right)+2 \mathrm{ClOH}(
\end{gathered}
$$

Concentrated hypochlorous acid solution can be obtained by filtering the reaction liquid and vacuum distillation.

Here are the bond dissociation enthalpy data for some Chemical Bonds [2]. The bond dissociation enthalpy of a Chemical Bond is the minimum energy required to break a Chemical Bond of one mole. It can also be approximated as the minimum activation energy $\left(E_{\mathrm{a}}\right)$ required to break a mole of the bond (the upper and lower corner " $\mathrm{r}$ " represents the chemical reaction, the letter " $H$ " represents the enthalpy of the chemical thermodynamic function, and the corner " $\mathrm{g}$ " represents the gas).

$$
\mathrm{Cl}-\mathrm{Cl}_{(\mathrm{g})} \rightarrow \cdot \mathrm{Cl}_{(\mathrm{g})}+\cdot \mathrm{Cl}_{(\mathrm{g})} \Delta_{\mathrm{r}} H^{\Theta}=242.58 \mathrm{kJmol}^{-1}
$$

$$
\begin{gathered}
\mathrm{ClOH} \rightarrow \cdot \mathrm{Cl}+\cdot \mathrm{OH} \quad \Delta_{\mathrm{r}} H^{\ominus}=126.7 \mathrm{kJmol}^{-1} \\
\mathrm{ClOH} \rightarrow \cdot \mathrm{H}+\mathrm{ClO} \cdot \Delta_{\mathrm{r}} H^{\ominus}<502.0 \mathrm{kJmol}^{-1} \\
\mathrm{OH} \rightarrow \cdot \mathrm{O} \cdot+\cdot \mathrm{H} \quad \Delta_{\mathrm{r}} H^{\ominus}=463 \mathrm{kJmol}^{-1} \\
\mathrm{ClO} \cdot \rightarrow \cdot \mathrm{Cl}+\cdot \mathrm{O} \cdot \Delta_{\mathrm{r}} H^{\Theta}=268.98 \mathrm{kJmol}^{-1} \\
\mathrm{Cl}-\mathrm{O}-\mathrm{O} \cdot \rightarrow \cdot \mathrm{Cl}+\mathrm{O}_{2} \Delta_{\mathrm{r}} H^{\ominus}=26.0 \mathrm{kJmol}^{-1} \\
{[\mathrm{Cl}-\mathrm{O}]^{-} \rightarrow \mathrm{Cl}^{-}+\cdot \mathrm{O} \cdot \Delta_{\mathrm{r}} H^{\Theta}=209.2 \mathrm{kJmol}^{-1}}
\end{gathered}
$$

From the data of enthalpy change of chemical bond dissociation process mentioned above, it can be seen that the bond dissociation enthalpy of $\mathrm{Cl}-\mathrm{Cl}$ bond in chlorine gas molecule and $\mathrm{O}-\mathrm{Cl}$ bond in hypochlorite molecule is not very large. Combined with the photosensitive properties of $\mathrm{Cl}-\mathrm{Cl}$ bonds in chlorine molecules and $\mathrm{O}-\mathrm{Cl}$ bonds in hypochlorous acid molecules, the activation energy required for dissociation of chemical bonds will be greatly reduced under the disturbance of external fields (such as light) and the polarity of water molecules, and the breaking of chemical bonds will become possible. In addition, once a process is initiated, it may cause other chemical bonds to break through synergistic effect and chain effect transfer, even if the process is very weak, but it is likely to exist. Therefore, it is speculated that the following weak processes are most likely to occur in chlorine aqueous solution:

$$
\begin{gathered}
\mathrm{Cl}_{2} \rightarrow \cdot \mathrm{Cl} \\
\mathrm{ClOH} \rightarrow \mathrm{H}^{+}+\mathrm{Cl}^{-}+\cdot \mathrm{O} \cdot \\
2 \mathrm{ClOH} \rightarrow \cdot \mathrm{Cl}+\cdot \mathrm{O} \cdot+\mathrm{H}_{2} \mathrm{O} \\
2 \mathrm{ClOH} \rightarrow \mathrm{Cl}_{2} \mathrm{O}+\mathrm{H}_{2} \mathrm{O} \\
\mathrm{ClOH} \rightarrow \cdot \mathrm{Cl}+\cdot \mathrm{OH} \\
\mathrm{ClOH} \rightarrow \mathrm{ClO} \cdot+\cdot \mathrm{H} \\
\mathrm{O} \cdot+\cdot \mathrm{OH} \rightarrow \cdot \mathrm{O}_{2} \mathrm{H} \\
\mathrm{O}_{2} \mathrm{H}+\mathrm{H}_{2} \mathrm{O} \rightarrow \cdot \mathrm{OH}+\mathrm{H}_{2} \mathrm{O}_{2} \\
\mathrm{O} \cdot+\mathrm{H}_{2} \mathrm{O} \rightarrow \mathrm{H}_{2} \mathrm{O}_{2}
\end{gathered}
$$

Free radicals generated in the above process: $\cdot \mathrm{Cl}, \mathrm{O}, \cdot \mathrm{OH}$, $\mathrm{O}_{2} \mathrm{H}$ are highly oxidative particles (active radicals refer to atoms, clusters or molecules containing single electrons).

[Summary] As mentioned above, chlorine aqueous solution is a complex redox system composed of many molecules, ions and free radicals. Because there may be many strong oxidizing ions in chlorine water, it is not difficult to understand the reason why chlorine water has strong oxidizing ability.

\section{Study on Bleaching Effect of Chlorine Water}

Although the strength of hypochlorous acid is relatively low ( $p K_{\mathrm{a}}=7.5$; operator: $p=-\lg ; K_{\mathrm{a}}$ represents the ionization 
constant of acid), according to the electrode potential value of redox pair: $E^{\theta}\left(\mathrm{ClOH} / \mathrm{Cl}^{-}\right)=1.50 \mathrm{~V}, E^{\theta}\left(\mathrm{ClOH} / \mathrm{Cl}_{2}\right)=1.63 \mathrm{~V}$, it can be seen that hypochlorous acid has strong oxidation ability. Therefore, it is reasonable to think that the bleaching effect of chlorine aqueous solution is caused by strong oxidized hypochlorous acid. Then, through what mechanism is the strong oxidation of hypochlorous acid achieved? Does hypochlorous acid have any other effects besides strong oxidation? What are the functions of other components in chlorine water? The following experimental exploration and corresponding principle analysis will give you some inspiration. Please correct the inappropriateness.

Before proceeding, it is necessary to explain the principle of organic dyes on red paper strips used in this paper, as follows:

The color of matter is produced by the interaction between light and matter, which is essentially the result of the transition of electrons in matter between different energy levels. The causes of color can be summarized as the selective absorption and emission of light by matter, and the physical processes of reflection, transmission and scattering when light propagates in matter. The color of matter is the comprehensive effect of the above processes on human visual perception.

There are conjugated systems of single bond and double bond alternately arranged in the molecules of organic dyes, forming out-of-domain bonds with multi-atoms sharing multi-electrons. When the conjugation degree of the conjugated system is large enough (for example, the off-domain conjugated system with dozens or dozens of atoms), the difference between the highest energy occupied molecular orbital (HOMO) and the lowest energy empty molecular orbital (LUMO) is equivalent to that in the visible band (energy:4.97 $\times 10^{-19} \mathrm{~J} \sim 2.74 \times 10^{-19} \mathrm{~J}$; wavelength:400nm $730 \mathrm{~nm}$ ), the color of the molecule will occur. The color of organic dyes is caused by the delocalization of the conjugated molecules, which is the result of the transition of electrons between different molecular orbitals. Therefore, the conjugated structure of organic dyes is called "chromophore group". It is true that in order to fade organic dyes, every effort must be made to destroy their "chromogenic groups".

\subsection{Bleaching Effect of New Chlorine Water (Source Experiment or Blank Experiment)}

Chlorine gas was prepared by the reaction of manganese Dioxide $\left(\mathrm{MnO}_{2}\right)$ with concentrated Hydrochloric Acid ( $\left.\mathrm{HCl}\right)$. Then, the chlorine gas obtained is sequentially passed through the saturated sodium chloride aqueous solution and concentrated Sulfuric Acid to remove Hydrogen Chloride and water vapor, and then pure Chlorine Gas can be obtained. The chlorine gas is put into the wide-mouth bottle containing distilled water to obtain "saturated chlorine water". The red paper coated with red organic dyes is put into a wide-mouth bottle containing "saturated chlorine water". The volume of "saturated Chlorine Water" in the wide-mouth bottle accounts for about one third of the bottle volume. Immerse the red strip in Chlorine Water and cover the bottle with ground glass. It can be seen that the red color of the section immersed in Chlorine Water gradually becomes lighter and almost completely fades after about an hour. However, the red color of the strip exposed to the upper part of the chlorine solution only lightens, but does not fade completely. This shows that both chlorine water and moist chlorine have bleaching effect, but the bleaching efficiency is different.

\subsection{Dry Chlorine Has No Bleaching Effect (Contrast Experiment, the Same as Below)}

A proper amount of desiccant calcium chloride $\left(\mathrm{CaCl}_{2}\right.$ (s) $)$ is put into a wide-mouth bottle (in order to prevent the chemical reaction between cobalt chloride $\left(\mathrm{CoCl}_{2}\right)$ and chlorine gas $\left(\mathrm{Cl}_{2}\right)$, no discolored silica gel is used as desiccant). Then the pure chlorine gas dried with concentrated sulfuric acid is collected in a wide-mouth bottle. When chlorine gas is filled, the red strip is put into the bottle immediately. At the same time, seal the bottle with a rubber plug, wrap it in a black plastic bag and place it in the dark. A week later, it was found that the color of the red strip did not change significantly, indicating that the dry chlorine had no bleaching effect.

\subsection{Long-standing Chlorine Water Loses Its Bleaching Effect}

In a wide-mouth bottle, the newly prepared saturated chlorine water is filled, and the volume of saturated chlorine water accounts for about one third of the volume of the wide-mouth bottle. The $p \mathrm{H}$-sensor is put into saturated chlorine water. When the sensor reading is stable, the measured value of saturated chlorinated water $\mathrm{pH}$ value is about 1.50 . Then cover the jar with a glass stopper and expose it to the sun. Four weeks later, the $p \mathrm{H}$ value of the solution was about 1.05 again measured by the $p \mathrm{H}$-sensor, and the acidity of the solution increased significantly. Place the red strip in the solution of the bottle again and cover it with ground glass. An hour later, it was found that the color of red stripes became lighter, but did not fade. It was obvious that the bleaching effect was greatly weakened. Therefore, it can be presumed that chlorine water placed for a long time will gradually lose its bleaching effect.

[Analysis] Firstly, the concentration of hypochlorous acid in chlorine water at $p \mathrm{H}=1.05$ was calculated. Because of the $p \mathrm{H}=1.05$, the concentration of hydrogen ion in chlorine water is: $C\left(\mathrm{H}^{+}\right)=0.089 \mathrm{molL}^{-1}$. Under this condition, the possible chemical reaction in solution is: $2 \mathrm{Cl}_{2}+2 \mathrm{H}_{2} \mathrm{O} \rightarrow 4 \mathrm{H}^{+}+4 \mathrm{Cl}^{-}+\mathrm{O}_{2}$.

It is concluded that the concentration of Chlorine Gas participating in the reaction is: $C\left(\mathrm{Cl}_{2}\right)=0.045 \mathrm{molL}^{-1}$. From the previous discussion, the concentration of chlorine in saturated chlorine water is known to be: $C\left(\mathrm{Cl}_{2}\right)=0.093 \mathrm{molL}^{-1}$. After 4 weeks of illumination, the concentration of chlorine decreased as follows: $C\left(\mathrm{Cl}_{2}\right)=0.045 \mathrm{~mol} \mathrm{~L}^{-1}$. Therefore, the concentration of residual chlorine without reaction was: $C\left(\mathrm{Cl}_{2}\right)=0.047 \mathrm{~mol}$ $\mathrm{L}^{-1}$. At this time, the concentration of chlorine ion in chlorine water was: $C\left(\mathrm{Cl}^{-}\right)=0.09 \mathrm{molL}^{-1}$. According to the corresponding disproportionation reaction:

$\mathrm{Cl}_{2}+\mathrm{H}_{2} \mathrm{O} \rightarrow \mathrm{H}^{+}+\mathrm{Cl}^{-}+\mathrm{ClOH}$, the equilibrium constant at 298K:

$K^{\theta}=4.2 \times 10^{-4}[2] 126, C\left(\mathrm{H}^{+}\right) C\left(\mathrm{Cl}^{-}\right) C(\mathrm{HOCl}) / C\left(\mathrm{Cl}_{2}\right)=4.2 \times 10^{-4}$ 
the above relevant data is substituted into the equation, that is,

$$
0.089 \times 0.090 \times C(\mathrm{ClOH}) / 0.047=4.2 \times 10^{-4}
$$

further calculated: $C(\mathrm{ClOH})=2.3 \times 10^{-3} \mathrm{molL}^{-1}$. It was found that the concentration of hypochlorous acid in chlorine water was less than one tenth of the concentration of hypochlorous acid before illumination $\left[C(\mathrm{ClOH})=0.031 \mathrm{molL}^{-1}\right]$. If placed for a long time, the concentration of hypochlorous acid would continue to decrease and chlorine water would lose its bleaching effect.

Secondly, the above changes are explain theoretically. The chlorine gas dissolved in water can react with water in the following two types of chemical reactions:

$$
2 \mathrm{Cl}_{2}+2 \mathrm{H}_{2} \mathrm{O} \rightarrow 4 \mathrm{H}^{+}+4 \mathrm{Cl}^{-}+\mathrm{O}_{2} \text { Displacement reaction }
$$

$\mathrm{Cl}_{2}+\mathrm{H}_{2} \mathrm{O} \rightarrow \mathrm{H}^{+}+\mathrm{Cl}^{-}+\mathrm{ClOH}$ Disproportionation reaction

The decrease of concentration of hypochlorous acid is mainly caused by type (35) Displacement reaction. Thermodynamic analysis of Type (35) displacement reaction is carried out here. The corresponding thermodynamic data are as follows:

$$
\begin{gathered}
1 / 2 \mathrm{Cl}_{2}+\mathrm{e}^{-} \rightarrow \mathrm{Cl}^{-} E^{\Theta}\left(\mathrm{Cl}_{2} / \mathrm{Cl}^{-}\right)=1.358 \mathrm{~V} \\
1 / 2 \mathrm{O}_{2}+2 \mathrm{H}^{+}+2 \mathrm{e}^{-} \rightarrow \mathrm{H}_{2} \mathrm{O} E^{\Theta}\left(\mathrm{O}_{2} . \mathrm{H}^{+} / \mathrm{H}_{2} \mathrm{O}\right)=1.229 \mathrm{~V}
\end{gathered}
$$

According to the chemical thermodynamic equation (In the following mathematical expressions, $G$ denotes "Gibbs free energy" and $E$ denotes "electrode potential", and $\Delta_{\mathrm{r}} G$ denotes the change of Gibbs free energy of chemical reaction under standard state):

$$
\begin{gathered}
\Delta_{\mathrm{r}} \mathrm{G}^{\Theta}=-\mathrm{nF} \Delta \mathrm{E}^{\Theta} \\
\Delta E^{\Theta}=1.358 \mathrm{~V}-1.229 \mathrm{~V}=0.129 \mathrm{~V}>0
\end{gathered}
$$

so that

$$
\Delta_{\mathrm{r}} G^{\Theta}<0
$$

therefore, from the chemical thermodynamic point of view, the displacement reaction of type (35) can be spontaneously carried out under the standard condition, that is, chlorine gas can oxidize water to oxygen; But from the chemical kinetics point of view, the displacement reaction of type (35) may have relatively high activation energy. It makes the reaction rate smaller under normal conditions. In fact, only under light can chlorine water produce oxygen slowly, which is actually due to the fact that chlorine molecules are photosensitive molecules, and this photosensitive property is very little affected by their own state. As long as the frequency of light matches, the photochemistry process can occur. Since the photochemical process is usually a chain reaction, the reaction is usually faster. The kinetics of photocatalytic process is described as follows:

$$
\text { Initiation: } \mathrm{Cl}_{2}+\text { photon } \rightarrow 2 \cdot \mathrm{Cl}
$$

Transmit: $\cdot \mathrm{Cl}+\mathrm{H}_{2} \mathrm{O} \rightarrow \mathrm{H}^{+}+\mathrm{Cl}^{-}+\cdot \mathrm{OH}$

$$
\begin{gathered}
\mathrm{OH}+\mathrm{HOCl} \rightarrow \mathrm{H}_{2} \mathrm{O}_{2}+\cdot \mathrm{Cl} \\
\mathrm{Cl}+\mathrm{H}_{2} \mathrm{O}_{2} \rightarrow \mathrm{H}^{+}+\mathrm{Cl}^{-}+\cdot \mathrm{O}_{2} \mathrm{H}
\end{gathered}
$$

Termination:

$$
\mathrm{Cl}+\mathrm{O}_{2} \mathrm{H} \rightarrow \mathrm{H}^{+}+\mathrm{Cl}^{-}+\mathrm{O}_{2}
$$

Total process:

$$
\begin{gathered}
2 \mathrm{Cl}+\mathrm{H}_{2} \mathrm{O}+\mathrm{HOCl}+\text { photon } \rightarrow 3 \mathrm{H}^{+}+3 \mathrm{Cl}^{-}+\mathrm{O}_{2} \\
\text { OR: } \mathrm{Cl}_{2}+\mathrm{H}_{2} \mathrm{O}+\mathrm{HOCl}+\text { photon } \rightarrow 3 \mathrm{H}^{+}+3 \mathrm{Cl}^{-}+\mathrm{O}_{2}
\end{gathered}
$$

It can be seen that under the catalysis of exogenous photons, chlorine molecules $\left(\mathrm{Cl}_{2}\right)$, water molecules $\left(\mathrm{H}_{2} \mathrm{O}\right)$ and hypochlorous acid molecules $(\mathrm{ClOH})$ in chlorine water are converted into hydrogen ions $\left(\mathrm{H}^{+}\right)$, chloride ions $\left(\mathrm{Cl}^{-}\right)$and oxygen molecules $\left(\mathrm{O}_{2}\right)$. The oxygen $(\mathrm{O})$ in the oxygen $\left(\mathrm{O}_{2}\right)$ molecule produced seems to come from water molecules $\left(\mathrm{H}_{2} \mathrm{O}\right)$ and hypochlorite molecules $(\mathrm{ClOH})$, but in the final analysis it is still. It comes from the water molecule $\left(\mathrm{H}_{2} \mathrm{O}\right)$. Unlike the decomposition of oxyacid, which usually produces corresponding oxides and water, the photodecomposition reaction of hypochlorite does not produce $\mathrm{Cl}_{2} \mathrm{O}$ and $\mathrm{H}_{2} \mathrm{O}$, and its photodecomposition complexity is conceivable. Besides the above processes, there may be other reactions in the system, such as

$$
\begin{aligned}
& \mathrm{ClOH}+\text { photon } \rightarrow \cdot \mathrm{Cl}+\cdot \mathrm{OH} \\
& \mathrm{Cl}+\mathrm{ClOH} \rightarrow \mathrm{H}^{+}+\mathrm{Cl}^{-}+\mathrm{ClO} .
\end{aligned}
$$

etc.

The existence of these reactions may be the possible reasons for further conversion of a small amount of hypochlorous Acid $(\mathrm{ClOH})$ to chloric Acid $(\mathrm{HClO} 3)$, which will not be discussed here.

Usually, chlorine reacts with water mainly (II), namely disproportionation reaction.

\subsection{Dry Chlorine Has No Bleaching Effect Under Long-term Sunlight Irradiation}

Adequate desiccant calcium chloride $\left(\mathrm{CaCl}_{2 \text { (s) }}\right.$ was added to the test tube, and then pure chlorine gas $\left[\mathrm{Cl}_{2}(\mathrm{~g})\right]$ was introduced. Immediately put a small piece of red paper into the test tube and tighten it with a rubber plug. Then the test tube was placed in direct sunlight. A week later, the color of the red strip did not fade, but only slightly lighter. This experiment proves that chlorine atoms (free radicals) have no bleaching effect.

[Analysis] Under illumination,

$$
\mathrm{Cl}_{2}+\text { photon } \rightarrow 2 \cdot \mathrm{Cl}
$$

the free radical $\mathrm{Cl}$ may result in the substitution of hydrogen $(\mathrm{H})$ on saturated carbon atoms of colored substances, i.e.

$$
\begin{aligned}
& \mathrm{R}-\mathrm{H}(\text { hydrocarbon bond })+\mathrm{Cl} \rightarrow \cdot \mathrm{R}+\mathrm{HCl} \\
& \mathrm{R}+\mathrm{Cl}_{2} \rightarrow \mathrm{R}-\mathrm{Cl}(\text { carbon chlorine bond })+\cdot \mathrm{Cl}
\end{aligned}
$$


This result did not destroy the basic structure of the chromophore group (conjugated double bond system) in the molecule of colored substance, but after all, the structure of the colored molecule was fine-tuned, and the secondary structure of the colored molecule was changed. Therefore, the wavelength and frequency of the light absorbed and emitted by the colored molecule would be slightly changed, resulting in a slight decrease in the intensity of its color. It should be pointed out that under light conditions, the addition reaction between free radicals and conjugated double bonds is relatively difficult, and there is also a need for peroxide (peroxide effect) to exist [3] 324-325. Therefore, under the above conditions, chlorine gas $\left[\mathrm{Cl}_{2(\mathrm{~g})}\right]$ will not destroy the free radical addition reaction of conjugated double bond system.

\subsection{The Bleaching Effect of Newly Prepared Hypochlorous Acid is Enhance}

A sufficient amount of sodium carbonate solid $\left(\mathrm{Na}_{2} \mathrm{CO}_{3(\mathrm{~s})}\right.$ is added to the conical bottle, and saturated chlorine water is continuously dripped onto the sodium carbonate solid in the conical bottle through a separating funnel. The resulting gas is absorbed into a sufficient amount of colorless carbon tetrachloride $\left(\mathrm{CCl}_{4}\right)$. When the color of carbon tetrachloride is dark brown and stable, the gas is stopped. Adding proper amount of distilled water to carbon tetrachloride, fully oscillating, stationary, stratified, until the lower layer of carbon tetrachloride is nearly colorless, the upper solution is a relatively "pure" hypochlorous acid solution. Put the red strip into the upper solution, and the red strip recedes a moment later. Compared with the previous experiment 3.1, the bleaching efficiency is higher. This experiment further confirmed that hypochlorous acid is the main bleaching agent in chlorine water.

$$
\begin{gathered}
\text { [Analysis] } \mathrm{Cl}_{2}+\mathrm{H}_{2} \mathrm{O} \leftrightharpoons \mathrm{H}^{+}+\mathrm{Cl}^{-}+\mathrm{ClOH} \\
2 \mathrm{Cl}_{2}+2 \mathrm{Na}_{2} \mathrm{CO}_{3}+\mathrm{H}_{2} \mathrm{O} \rightarrow \mathrm{Cl}_{2} \mathrm{O}_{(\mathrm{g})}+2 \mathrm{NaHCO}_{3}+2 \mathrm{NaCl}
\end{gathered}
$$

dichlorine monoxide $\left(\mathrm{Cl}_{2} \mathrm{O}(\mathrm{g})\right.$ is a light yellow-green gas, which can dissolve in carbon tetrachloride and show brown color, while chlorine $\left(\mathrm{Cl}_{2}\right)$ is insoluble in carbon tetrachloride. After adding water, $\mathrm{Cl}_{2} \mathrm{O}$ reacts with water $\left(\mathrm{H}_{2} \mathrm{O}\right)$ to form hypochlorous $\mathrm{Acid}(\mathrm{ClOH})$. As the density of carbon tetrachloride is higher than that of water, the upper layer is water layer and the lower layer is carbon tetrachloride layer:

$$
\mathrm{Cl}_{2} \mathrm{O}+\mathrm{H}_{2} \mathrm{O} \rightarrow \mathrm{ClOH}
$$

\subsection{The Bleaachinag Effect of Newly Prepared Chlorine Water Can Be Improve by Adding Appropriate Sodium Hydroxide Solution}

When the newly prepared saturated chlorine water is added into the clean wide-mouth bottle, the volume of chlorine water accounts for about one third of the volume of the wide-mouth bottle. Two drops of sodium hydroxide solution $\left(\mathrm{NaOH}_{(\mathrm{aq})}\right)$ with concentration of $2 \mathrm{molL}^{-1}$ were gradually added to chlorine water. The red strip was fully oscillated and stationary. The red strip was put into the above solution and then covered with ground glass. Compared with experiment 3.1, it was found that the color fading rate of the red strip was obviously accelerated.

[Analysis] In fact, the essence of the reaction between chlorine gas $\left(\mathrm{Cl}_{2}\right)$ and water $\left(\mathrm{H}_{2} \mathrm{O}\right)$ is:

$$
\mathrm{Cl}_{2}+\mathrm{OH}^{-} \leftrightharpoons \mathrm{Cl}^{-}+\mathrm{ClOH}
$$

The study of chemical kinetics shows that the differential equation of hydrolysis rate is [2](The " $r$ " in the following mathematical expression represents the rate of chemical reaction):

$$
\left.r=\mathrm{d}[C(\mathrm{ClOH})] / \mathrm{dt}=K_{1} C \mathrm{Cl}_{2}\right) C\left(\mathrm{OH}^{-}\right)-K_{2} C\left(\mathrm{Cl}^{-}\right) C(\mathrm{ClOH})
$$

In which $K_{1}$ and $K_{2}$ were constant [2]213. Because of the reversibility of the above reaction, increasing the concentration of hydroxide ion $\left(\mathrm{OH}^{-}\right)$de can make the increase of $K_{1} C\left(\mathrm{Cl}_{2}\right) C\left(\mathrm{OH}^{-}\right)$exceed the increase of $K_{2} C\left(\mathrm{Cl}^{-}\right) C(\mathrm{HOCl})$ in a certain range. In this range, the increase of the concentration of hydroxide ion will increase the reaction rate, that is: $\Delta r>0$, the formation rate of hypochlorous $\operatorname{acid}(\mathrm{ClOH})$ was increased, that is, the rate of increasing the concentration of hypochlorous acid $(\mathrm{ClOH})$ was accelerated, and then the bleaching rate was accelerated, and the bleaching efficiency was improved. Of course, if the concentration of hydroxide ion exceeds a certain range, the concentration of hypochlorite will decrease (why? I would like to invite interested friends to continue to analyze and demonstrate). As for the best concentration range of hydroxide ions, strict mathematical deduction and experimental proof are needed. In addition, in what $\mathrm{pH}$ range, hypochlorite concentration is the highest? It is also a subject that we need to study and demonstrate. Interested friends can continue to study with me.

\section{Comprehensive Analysis}

Through the above research, we can see that the bleaching of chlorine water is a process of synergistic action of various components, and there are many influencing factors, such as temperature, $\mathrm{pH}$ value, light, a variety of free radicals and so on. Although the process of bleaching is very complex, but the original source is clear, "the main role" is still hypochlorous Acid $(\mathrm{ClOH})$. Following a summary of the next hypochlorous Acid $(\mathrm{ClOH})$ bleaching action principle:

(1) The main effect is to destroy the whole structure of the coloured molecule through the strong oxidation of hypochlorous Acid $(\mathrm{ClOH})$, which may lead to the fragmentation of the coloured molecule and make it lose its colour. Moreover, this oxidation is probably achieved by the strong oxidizing atomic oxygen $[\mathrm{O}]$ polarized by hypochlorous Acid $(\mathrm{ClOH})$.

(2) The electrophilic addition of conjugated double bond system by hypochlorous Acid $(\mathrm{ClOH})$ should also play an important role in destroying the chromogenic groups in organic molecules.

(3) Halogenated hydrogen atoms $(\mathrm{H})$ on carbon-hydrogen bonds $(\mathrm{C}-\mathrm{H})$ are destroyed by hypochlorous Acid 
$(\mathrm{ClOH})$ to destroy the secondary structure of nonferrous molecules. Although this effect may not cause discoloration, it may play an additional role in the bleaching process. This process belongs to the action mechanism of free radicals. The analysis is as follows for reference.

$$
\begin{gathered}
\mathrm{ClOH} \leftrightharpoons \cdot \mathrm{Cl}+\mathrm{OH} \\
\mathrm{RH}+\cdot \mathrm{Cl} \rightarrow \mathrm{HCl}+\mathrm{R} \\
\mathrm{HCl}+\mathrm{ClOH} \leftrightharpoons \mathrm{H}_{2} \mathrm{O}+\mathrm{Cl}_{2} \\
\mathrm{R}+\mathrm{Cl}_{2} \rightarrow \mathrm{RCl}+\mathrm{Cl}
\end{gathered}
$$

[Suggestion] From the above discussion, it can be seen that the microchemistry process of chlorine water bleaching is irreversible. Therefore, the process of chlorine water bleaching is irreversible. That is to say, it is impossible to restore the original color after chlorine bleaching. The bleaching effect of chlorine water has substantial "destructive" to the bleaching object. The bleaching mechanism of chlorine water and sulfur dioxide $\left(\mathrm{SO}_{2}\right)$ aqueous solution is different, the suitable bleaching objects are different, and the results are different, so it should be distinguished.

In summary, the purpose of this paper is to reveal the essence of chlorine bleaching comprehensively, thoroughly and scientifically by exploring the experiment and explaining the principle of chlorine bleaching. Because of the complexity of Chlorine-Water system itself and the difficulty of thermodynamic analysis, kinetic analysis and structural analysis, the research is still superficial. Based on this, the mistakes need to be corrected by colleagues. The author will be grateful.

\section{References}

[1] Liu Xin-Jin, Zhu Ya-Xian, Gao Fei. Inorganic Element Chemistry. Beijing: Science Press, 2005: pp 126-126.

[2] Zhong Xing-Hou, Xiao Wen-Jin, Yuan Qi-Hua, et al. Series on Inorganic Chemistry (Volume 6). Beijing: Science Press, 2012: pp 213-213.
[3] Xing Qi-Yi, Pei Wei-Wei, Xu Rui-Qiu et al. Basic Organic Chemistry (Volume 1). 3 Edition. Beijing: Higher Education Press, 2005: pp 324-325.

[4] Liu Wei-Sheng (Editor-in-Chief). Coordination Chemistry: Chemical Industry Press, 2013.

[5] Douglas John Newman, Betty Wu Doug. Handbook of Crystal Field: China University of Science and Technology Press, 2012.

[6] John P Lowe, Kirk A. Peterson. Quantun Chemistry (third edition): Elsevier (Singapore) Pte Ltd, World Book Publishing Company, 2011.

[7] Xu Guang-Xian, Wang Xiang-Yun. Material Structure: Science Press, 2013.

[8] Zhang Gui-Ling, (editor-in-chief), Yang Zhao-Di, Sun Miao, Yuan Dan-Dan. Fundamentals of Quantum Chemistry: Chemical Industry Press, 2012.

[9] Zhao Xin-Sheng. Introduction to Chemical Reaction Theory: Peking University Press, 2004.

[10] Ying Bai-Ning, Song Hua-Can. Physical Organic Chemistry: Chemical Industry Press, 2009.

[11] Wang Jian-Bo. Concise Course of Physical Organic Chemistry: Peking University Press, 2013.

[12] Sheila R. Buxton, Stanley M. Roberts. Guide to Stereochemistry: Chemical Industry Press, 2007.

[13] Gong Zhu-Qing and Wang Zhi-Xing. Modern electrochemistry: Central South University Press, 2010.

[14] Zhou Gong-Du. Structure and Physical Property: Higher Education Press, 2002.

[15] Shen Pan-Wen (Editor in Chief), Yang Hong-Xiu, Che Yun-Xia, Cheng Peng and Liu Xin. Introduction to Modern Chemistry: Higher Education Press, 2002.

[16] Fu Xiang-Jian (chief editor), Liu-Qun (deputy editor), Zhou Li-Ren (deputy editor). Higher Organic Chemistry: Higher Education Press, 2003. 